\title{
RELATIONS BETWEEN THE QUALITY OF HEALTH SERVICES WITH OUTPATIENT LOYALTY IN POLY OBGYN RSIA ERIA PEKANBARU IN 2016
}

\author{
Leon Candra, Rosi Hairati \\ Studies course in Public Health Sciences STIKes Hang Tuah Pekanbaru \\ Email: leon_candra@htp.ac.id
}

\begin{abstract}
Customer loyalty is a person who buys, especially purchase regularly and repeat edly (Hassan, 2008). The purpose of this study is whet her there is a relationship of health service quality and out patient loyalty of poly OBGYN in RSIA Eria Bunda Pekanbaru 2016. This research method is quantitative analytic observational using cross-sectional design, respondents were out patients of poly OBGYN RSIA Eria Bunda Pekanbaru. The study sample as many as 97 out patients. The sampling technique is purposive sampling. The analysisis univariate and bivariate analysis using Chi-square, measuring instruments used were question naires and computerized data processing. The results showed anassociation between tangibles ( $p$ value $=0.046$ and POR $=2.9$ ), reliability $(p$ value $=0.007$, and POR $=4)$ and empathy $(p$ value $=0.031$, and POR = 3.4) with patient loyalty in the Poly Obgyn RSIA Eria Bunda Pekanbaru. The absence of a relationship between responsiveness ( $p$ value $=0.079$, and $P O R=0.3)$ and assurance $(p$ value $=0.593$, and POR =1.4) with patient loyalty in the Poli OBGYN RSIA Eria Bunda Pekanbaru. Suggested for RSIA Eria Bunda Pekanbaru need to do the training, disseminating feed back, criticisms, and suggestions of the patien/family and need to think about how to suppress deficiencies in service, equipment (tangible) to improve service quality, and human resources, that are expected to display the superior it service.
\end{abstract}

Keywords: Qualityof Service, Loyalty, RSIA Eria Bunda

\section{PENDAHULUAN}

Loyalitas pelanggan adalah sebagai orang yang membeli, khusunya yang membeli secara teratur dan berulang-ulang (Hasan,2008). Kotler dan Keller dalam Imasari (2009) menjelaskan bahwa konsumen akan loyal diukur melalui tiga hal yaitu merekomendasikan orang lain untuk membeli atau mereferensikan kepada orang lain (word of mouth), menolak menggunakan produk lain, atau menunjukkan kekebalan terhadap tarikan dari pesaing (reject another) dan berapa sering melakukan pembelian ulang (repeat purchasing).

Rumah sakit adalah salah satu fasilitas pelayanan kesehatan yang memiliki peran yang sangat strategis dalam upaya mempercepat peningkatan derajat kesehatan masyarakat Indonesia. Perang starategis diperoleh karena rumah sakit adalah fasilitas kesehatan yang padat teknologi dan padat pakar. Harus disadari bahwa tujuan utama kegiatan rumah sakit adalah melayani pasien dan keluarganya, dalam berbagai bentuk dan pelayanan (Aditama, 2010).

Dalam upaya meningkatkan derajat kesehatan masyarakat yang setinggi-tingginya dapat dilakukan dengan memberikan pelayanan kesehatan yang pada mulanya berupa upaya penyembuhan penyakit, kemudian secara berangsur-angsur berkembang kearah keterpaduan kesehatan untuk seluruh masyarakat dengan mengikutsertakan masyarakat secara luas yang mencakup promotif, preventif, kuratif dan rehabilitatif yang bersifat menyeluruh, terpadu dan berkesinambungan (UU RI N0. 44 Tahun 2009).

Loyalitas merupakan hal yang penting dibangun setiap rumah sakituntuk memenangkan kompetisi. Apalagi menurut Reicheld dan Sasser dalam Suhartanto (2008) mengemukakan bahwa peningkatan 5\% dalam kesetiaan pelanggan dapat meningkatkan keuntungan sebesar 25\% sampai dengan $85 \%$, dan $60 \%$ peningkatan penjualan kepada konsumen baru adalah atas rekomendasi pelanggan yang loyal terhadap perusahaan. Loyalitas merupakan salah satu kunci sukses dalam memenangkan persaingan bisnis saat ini.

Kualitas pelayanan adalah tingkat keunnggulan yang diharapkan dan pengendalian atas tingkat keunggulan tersebut dalam memenuhi keinginan pelanggan. Ada dua faktor yang mempengaruhi kualitas pelayanan yaitu expected service dan perceived service. Apabila 
jasa yang diterima atau dirasakan (perceived service) sesuai dengan yang diharapkan, maka kualitas pelayanan akan dinilai baik dan memuaskan. Jika kualitas pelayanan yang diterima melampaui harapan pelanggan,maka kualitas pelayanan dinilai sebagai kualitas yang ideal, sebaliknya bila kualitas pelayanan yang diterima lebih rendah dari yang diharapkan, maka kualitas pelayanan dinilai buruk.Lima dimensi pokok kualitas pelayanan menurut Parasuraman yaitu bukti langsung meliputi fasilitas fisik, perlengkapan, pegawai dan sarana komunikasi, keandalan (reliability) yaitu kemampuan memberikan pelayanan yang dijanjikan dengan segera, akurat dan memuaskan, daya tanggap (responsiveness) yaitu keinginan para staff untuk membantu para pelanggan dan memberikan pelayanan dengan tanggap, jaminan (assurance) mencakup pengetahuan,kemampuan,kesopanan dan sifat dapat dipercaya yang dimiliki para staff, bebas dari bahaya, resiko dan keragu raguan, empati meliputi kemudahan dalam melakukan hubungan, komunikasi yang baik, perhatian pribadi dan memahami kebutuhan para pelanggan. (Banjarmasin Post, 2003)

Dari hasil survei awal dengan mewawancarai pasien rawat jalan di poli obgyn RSIA Eria Bunda, mengenai bukti langsung, kehandalan, daya tanggap, jaminan, dan perhatian pada bulan Maret 2016 terhadap 20 pasien rawat jalan di Rumah Sakit Eria Bunda diperoleh pasien lama yang tidak loyal terhadap rumah sakit yaitu 13 pasien $(65 \%)$ dan pasien yang loyal 7 pasien (35\%).

Tujuan penelitian ini adalah diketahuinya Hubungan antara Mutu Layanan Kesehatan Dengan Loyalitas Pasien Rawat Jalan di Poli Obgyn RSIA Eria Bunda Pekanbaru Tahun 2016.

\section{METODOLOGI ENELITIAN}

Jenis penelitian ini adalah kuantitatif analitik observasional dengan menggunakan desain penelitian cross sectional yang dilaksanakan bulan januari sampai maret di RSIA Eria Bunda Pekanbaru. Jumlah sampel dalam penelitian ini adalah yaitu sebanyak 97 orang. Analisis data dilakukan dengan system kompeterisasi SPSS dengan uji Chi- Square.

\section{HASIL DAN PEMBAHASAN}

Hasil

Analisis Univariat

\section{Tabel 1}

Distribusi Frekuensi Variabel Dependen dan Independen Hubungan Mutu Pelayanan dan Loyalitas Pasien Rawat Jalan Poli Obgyn RSIA Eria Bunda Pekanbaru Tahun 2016

\begin{tabular}{|c|c|c|c|}
\hline No & $\begin{array}{c}\text { Karakteristik } \\
\text { Responden }\end{array}$ & Frekuensi & $\begin{array}{c}\text { Persentase } \\
(\%)\end{array}$ \\
\hline \multirow[t]{4}{*}{1.} & Loyalitas & & \\
\hline & Tidak Loyal & 26 & 26,8 \\
\hline & Loyal & 71 & 73,2 \\
\hline & Total & 97 & 100 \\
\hline \multirow[t]{3}{*}{2.} & Tangibles & & \\
\hline & Tidak Lengkap & 25 & 25,8 \\
\hline & Lengkap & 72 & 74,2 \\
\hline & Total & 97 & 100 \\
\hline \multirow[t]{4}{*}{3} & Reliability & & \\
\hline & Tidak Baik & 27 & 27,8 \\
\hline & Baik & 70 & 72,2 \\
\hline & Total & 97 & 100 \\
\hline \multirow[t]{4}{*}{4} & Responsiveness & & \\
\hline & Tidak Baik & 30 & 30,9 \\
\hline & Baik & 67 & 69,1 \\
\hline & Total & 97 & 100 \\
\hline \multirow[t]{3}{*}{5} & Assurance & & \\
\hline & Tidak Baik & 35 & 36,1 \\
\hline & Baik & 62 & 63,9 \\
\hline \multirow[t]{4}{*}{6} & Empaty & & \\
\hline & Tidak Baik & 21 & 21,6 \\
\hline & Baik & 76 & $\mathbf{7 8 , 4}$ \\
\hline & Total Total & 97 & 100 \\
\hline
\end{tabular}

Berdasarkan tabel 1 dapat dilihat bahwa pasien yang tidak loyal sebanyak 26 orang (26,8 $\%$ ), pasien yang menyatakan tangibles tidak lengkap sebanyak 25 orang $(25,8 \%)$, pasien yang menyatakan reliability tidak baik sebanyak 27 orang $(27,8 \%)$, pasien yang menyatakan responsiveness tidak baik sebanyak 30 orang $(30,9 \%)$, pasien yang menyatakan assurance tidak baik sebanyak 35 orang $(36,1 \%)$, dan pasien yang menyatakan empaty tidak baik sebanyak 21 orang $(21,6 \%)$. 


\section{Analisa Bivariat}

Tabel 2

Hubungan Tangibles Dengan Loyalitas Pasien Rawat Jalan Poli Obgyn RSIA Eria Bunda Kota Pekanbaru Tahun 2016

\begin{tabular}{cccccccccc}
\hline \multirow{2}{*}{ Tangibles } & \multicolumn{4}{c}{ Loyalitas Pasien } & & \multirow{2}{*}{ Total } & \multirow{2}{*}{ P Value } & \multirow{2}{*}{$\begin{array}{c}\text { POR 95\% } \\
\text { CI }\end{array}$} \\
\cline { 2 - 7 } & \multicolumn{2}{c}{ Tidak Loyal } & \multicolumn{2}{c}{ Loyal } & & & \\
\cline { 2 - 7 } & $\mathbf{n}$ & $\mathbf{\%}$ & $\mathbf{n}$ & $\mathbf{\%}$ & $\mathbf{N}$ & $\mathbf{\%}$ & & \\
Tidak & 11 & 44 & 14 & 56 & 25 & 100 & & $2,9(1,128-$ \\
Lengkap & & & & & & & 0,046 & $7,901)$ \\
Lengkap & 15 & 20,8 & 57 & 79,2 & 72 & 100 & & \\
\hline Total & 26 & 26,8 & 71 & 73,2 & 97 & 100 & & \\
\hline
\end{tabular}

Berdasarkan Tabel 2 diketahui dari 97 bahwa 25 pasien yang menyatakan dengan tangibles petugas yang tidak lengkap sebanyak 11 orang (44\%) pasien yang tidak loyal, sementara itu dari 97 bahwa 72 pasien yang menyatakan tangibles petugas yang lengkap ada 15 orang $(20,8 \%)$ pasien yang menyatakan tidak loyal.

Hasil analisis statistik dengan uji chi square diperoleh $\mathrm{p}$ value $=0,046(p<0,05)$ artinya ada hubungan yang signifikan antara tangibles dengan loyalitas pasien. Analisis perbandingan hubungan kedua variabel diperoleh $\mathrm{POR}=2,9$ artinya pasien yang menyatakan tangibles petugas yang tidak lengkap mempunyai peluang tidak loyal 2,9 kali dibandingkan dengan pasien yang menyatakan tangibles petugas yang lengkap.

Tabel 3

Hubungan Reliability Dengan Loyalitas Pasien Rawat Jalan Poli Obgyn RSIA Eria Bunda Kota Pekanbaru Tahun 2016

\begin{tabular}{|c|c|c|c|c|c|c|c|c|}
\hline \multirow{2}{*}{ Reliability } & \multicolumn{4}{|c|}{ Loyalitas Pasien } & \multirow{2}{*}{\multicolumn{2}{|c|}{ Total }} & \multirow{3}{*}{ P Value } & \multirow{2}{*}{$\begin{array}{c}\text { POR 95\% } \\
\text { CI }\end{array}$} \\
\hline & \multicolumn{2}{|c|}{ Tidak Loyal } & \multicolumn{2}{|c|}{ Loyal } & & & & \\
\hline & $\mathbf{n}$ & $\%$ & $\mathbf{n}$ & $\%$ & $\mathbf{N}$ & $\%$ & & \\
\hline Tidak Baik & 13 & 48,1 & 14 & 51,9 & 27 & 100 & & \\
\hline Baik & 13 & 18,6 & 57 & 81,4 & 70 & 100 & & $10,695)$ \\
\hline Total & 26 & 26,8 & 71 & 73,2 & 97 & 100 & & \\
\hline
\end{tabular}

Berdasarkan Tabel 3 diketahui dari 97 bahwa 27 pasien yang menyatakan reliability petugas yang tidak baik sebanyak 13 orang $(48,1 \%)$ pasien yang tidak loyal, sementara itu dari 97 bahwa 70 pasien yang menyatakan reliability petugas yang baik ada 13 orang $(18,6 \%)$ paien yang menyatakan tidak loyal.

Hasil analisis uji statistik dengan uji chi square diperoleh $\mathrm{p}$ value $=0,007(p<0,05)$ artinya

Tabel 4

Hubungan Responsiveness Dengan Loyalitas Pasien Rawat Jalan Poli Obgyn RSIA Eria Bunda Kota Pekanbaru Tahun 2016

\begin{tabular}{|c|c|c|c|c|c|c|c|c|}
\hline \multirow{3}{*}{ Responsiveness } & \multicolumn{4}{|c|}{ Loyalitas Pasien } & \multirow{2}{*}{\multicolumn{2}{|c|}{ Total }} & \multirow{3}{*}{ P Value } & \multirow{3}{*}{$\begin{array}{l}\text { POR } \\
95 \% \text { CI }\end{array}$} \\
\hline & \multicolumn{2}{|c|}{ Tidak Loyal } & \multicolumn{2}{|c|}{ Loyal } & & & & \\
\hline & $\mathbf{N}$ & $\%$ & $\mathbf{n}$ & $\%$ & $\mathrm{n}$ & $\%$ & & \\
\hline Tidak Baik & 4 & 13,3 & 26 & 86,7 & 30 & 100 & 0.079 & \\
\hline
\end{tabular}

ada hubungan yang signifikan antara reliability dengan loyalitas pasien. Analisis perbandingan hubungan kedua variabel diperoleh $\mathrm{POR}=4$, artinya pasien yang menyatakan reliability petugas yang tidak baik mempunyai peluang tidak loyal 4 kali dibandingkan dengan pasien yang menyatakan reliability petugas yang baik. 


\begin{tabular}{|c|c|c|c|c|c|c|c|c|}
\hline \multirow{3}{*}{ Responsiveness } & \multicolumn{4}{|c|}{ Loyalitas Pasien } & \multirow{2}{*}{\multicolumn{2}{|c|}{ Total }} & \multirow{3}{*}{ P Value } & \multirow{3}{*}{$\begin{array}{l}\text { POR } \\
95 \% \text { CI }\end{array}$} \\
\hline & \multicolumn{2}{|c|}{ Tidak Loyal } & \multicolumn{2}{|c|}{ Loyal } & & & & \\
\hline & $\mathbf{N}$ & $\%$ & $\mathbf{n}$ & $\%$ & $\mathbf{n}$ & $\%$ & & \\
\hline Baik & 22 & 32,8 & 45 & 67,2 & 67 & 100 & & 0,3 \\
\hline Total & 26 & 26,8 & 71 & 73,2 & 97 & 100 & & $\begin{array}{l}(0,098- \\
1,014\end{array}$ \\
\hline
\end{tabular}

Berdasarkan Tabel 4 diketahui dari 97 bahwa 30 pasien yang menyatakan responsiveness petugas yang tidak baik sebanyak 4 orang $(13,3 \%)$ pasien yang tidak loyal, sementara itu dari 97 bahwa 67 pasien yang menyatakan responsiveness petugas yang baik ada 22 orang $(20,8 \%)$ pasien yang menyatakan tidak loyal.

Tabel 5

Hubungan Assurance Dengan Loyalitas Pasien Rawat Jalan Poli Obgyn RSIA Eria Bunda Kota Pekanbaru Tahun 2016

\begin{tabular}{|c|c|c|c|c|c|c|c|c|}
\hline \multirow{3}{*}{ Assurance } & \multicolumn{4}{|c|}{ Loyalitas Pasien } & \multirow{2}{*}{\multicolumn{2}{|c|}{ Total }} & \multirow{3}{*}{ P Value } & \multirow{2}{*}{$\begin{array}{l}\text { POR 95\% } \\
\text { CI }\end{array}$} \\
\hline & \multicolumn{2}{|c|}{ Tidak Loyal } & \multicolumn{2}{|c|}{ Loyal } & & & & \\
\hline & n & $\%$ & $\mathbf{n}$ & $\%$ & $\mathbf{n}$ & $\%$ & & \\
\hline Tidak Baik & 11 & 31,4 & 24 & 68,6 & 35 & 100 & & \\
\hline Baik & 15 & 24,2 & 47 & 75,8 & 62 & 100 & ),593 & \\
\hline Total & 26 & 26,8 & 71 & 73,2 & 97 & 100 & & \\
\hline
\end{tabular}

Berdasarkan Tabel 5 diketahui dari 97 bahwa 35 pasien yang menyatakan dengan assurance petugas yang tidak baik sebanyak 11 orang $(31,4 \%)$ pasien yang tidak loyal, sementara itu dari 97 bahwa 62 pasien yang menyatakan assurance petugas yang baik ada 15 orang $(24,2 \%)$ pasien yang menyatakan tidak loyal.

\section{Tabel 6}

Hubungan Empaty Dengan Loyalitas Pasien Rawat Jalan Poli Obgyn RSIA Eria Bunda Kota Pekanbaru Tahun 2016
Hasil analisis uji statistik dengan uji chi square diperoleh $\mathrm{p}$ value $=0,593(p \geq 0,05)$ artinya tidak ada hubungan yang signifikan antara assurance dengan loyalitas pasien.

\begin{tabular}{|c|c|c|c|c|c|c|c|}
\hline \multirow{3}{*}{ Empaty } & \multicolumn{4}{|c|}{ Loyalitas Pasien } & \multirow{2}{*}{ al } & \multirow{3}{*}{ P Value } & \multirow{3}{*}{$\begin{array}{c}\text { POR } \\
95 \% \mathrm{CI}\end{array}$} \\
\hline & \multicolumn{2}{|c|}{ Tidak Loyal } & \multicolumn{2}{|c|}{ Loyal } & & & \\
\hline & n & $\%$ & $\mathbf{n}$ & $\%$ & $\mathbf{N} \quad \%$ & & \\
\hline Tidak Baik & 10 & 47,6 & 11 & 52,4 & $21 \quad 100$ & & 3,4 \\
\hline Baik & 16 & 21,1 & 60 & 78,9 & 100 & 0,031 & $\begin{array}{c}(1,231- \\
9,441)\end{array}$ \\
\hline Total & 26 & 26,8 & 71 & 73,2 & 100 & & \\
\hline
\end{tabular}

Berdasarkan Tabel 6 diketahui dari 97 bahwa 21 pasien yang menyatakan empaty petugas yang tidak baik sebanyak 10 orang $(47,6 \%)$ pasien yang tidak loyal, sementara itu dari 97 bahwa 76 paisen yang menyatakan empaty yang baik ada 16 orang $(21,1 \%)$ pasien yang menyatakan tidak loyal.

Hasil analisis uji statistik dengan uji chi square diperoleh p value $=0,031(p \leq 0,05)$ artinya ada hubungan yang signifikan antara empaty 
dengan loyalitas pasien. Analisis perbandingan hubungan kedua variabel diperoleh POR $=3,4$, artinya pasien yang menyatakan empaty petugas yang tidak baik mempunyai peluang tidak loyal3,4 kali dibandingkan dengan pasien yang menyatakan empaty petugas yang baik.

\section{Pembahasan}

\section{a. Hubungan Tangibles Dengan}

Loyalitas Pasien Rawat Jalan Poli Obgyn RSIA Eria Bunda Kota Pekanbaru Tahun 2016

Berdasarkan hasil penelitian diketahui dari 97 bahwa 25 pasien yang menyatakan dengan tangibles petugas yang tidak lengkap sebanyak 11 orang (44\%) pasien yang tidak loyal, sementara itu dari 97 bahwa 72 pasien yang menyatakan tangibles petugas yang lengkap ada 15 orang $(20,8 \%)$ pasien yang menyatakan tidak loyal.

Hasil analisis statistik dengan uji chi square diperoleh pvalue $=0,046(p<0,05)$ artinya ada hubungan yang signifikan antara tangibles dengan loyalitas pasien. Analisis perbandingan hubungan kedua variabel diperoleh $\mathrm{POR}=2,9$.

Parasuraman (1985) dalam Tjiptono (2002) mengatakan bahwa tangibles merupakan ketersediaan sarana dan prasarana termasuk alat yang siap pakai serta penampilan karyawan/staf yang menyenangkan.Dimensi mutu pelayanan yang berupa penampilan fisik, seperti gedung dan ruangan front office, tersedianya tempat parkir, ruang tunggu, penampilan karyawan dan peralatan komunikasi.

Penelitian inisejalan dengan penelitian Sulni, dkk (2013) mengenai hubungan mutu pelayanan kesehatan dengan loyalitas pasien di Puskesmas Baranti Kabupaten Sidrap Tahun 2013 dengan hasil penelitian menunjukkan bahwa ada hubungan yang bermakna antara tangibles dengan loyalitas pasien p value $(0,001)$.

Berdasarkan data uraian diatas menurut asumsi peneliti, masih adanya responden yang menyatakan tangibles tidak baik disebabkan oleh ruang tunggu poli obgyn yang kurang bersih, hal ini dikarenakan jumlah petugas kebersihan di RSIA Eria Bunda masih kurang sehingga menyebabkan masih ditemukannya lantai yang kurang bersih sehingga mengganggu pasien.

Diharapkan kepada RSIA Eria Bunda untuk menambah petugas kebersihan agar terciptanya lingkungan yang bersih dan sehat, sehingga membuat pasien merasa nyaman.

\section{b. Hubungan Reliability Dengan Loyalitas Pasien Rawat Jalan Poli Obgyn RSIA Eria Bunda Kota Pekanbaru Tahun 2016}

Berdasarkan hasil penelitian diketahui dari 97 bahwa 27 pasien yang menyatakan reliability petugas yang tidak baik sebanyak 13 orang $(48,1 \%)$ pasien yang tidak loyal, sementara itu dari 97 bahwa 70 pasien yang menyatakan reliability petugas yang baik ada 13 orang $(18,6 \%)$ paien yang menyatakan tidak loyal.

Hasil analisis statistik dengan uji chi square diperoleh $\mathrm{p}$ value $=0,007(p<0,05)$ artinya ada hubungan yang signifikan antara reliability dengan loyalitas pasien. Analisis perbandingan hubungan kedua variabel diperoleh $\mathrm{POR}=4$.

Penelitian ini sejalan dengan penelitian Sulni, dkk (2013) mengenai hubungan mutu pelayanan kesehatan dengan loyalitas pasien di Puskesmas Baranti Kabupaten Sidrap Tahun 2013 dengan hasil penelitian menunjukkan bahwa ada hubungan yang bermakna antara reliability dengan loyalitas pasien $\mathrm{p}$ value $(0,001)$.

Parasuraman (1985) dalam Tjiptono (2002), Reliable merupakan kemampuan untuk memberikan pelayanan kesehatan dengan tepat waktu dan akurat sesuai dengan yang ditawarkan. Untuk meningkatkan reliability dibidang pelayanan kesehatan, pihak manajemen perlu membangun budaya kerja yang bermutu. Reliabilitas berkaitan dengan kemampuan menyampaikan layanan yang dijanjikan.

Menurut asumsi peneliti, masih adanya pasien yang menjawab reliable tidak baik dilapangan disebabkan karena pasien merasa kurang puas dengna penjelasan yang diberikan oleh petugas kesehatan. Sebaiknya RSIA Eria Bunda memberikan pelatihan atau penyuluhan kepada petugas mengenai cara berinteraksi dengan pasien sehingga pasien merasa puas dan loyal dengan pelayanan yang diberikan. 
c. Hubungan Responsiveness Dengan Loyalitas Pasien Rawat Jalan Poli Obgyn RSIA Eria Bunda Kota Pekanbaru Tahun 2016

Berdasarkan hasil penelitian diketahui dari 97 bahwa 30 pasien yang menyatakan responsiveness petugas yang tidak baik sebanyak 4 orang $(13,3 \%)$ pasien yang tidak loyal, sementara itu dari 97 bahwa 67 pasien yang menyatakan responsiveness petugas yang baik ada 22 orang $(20,8 \%)$ pasien yang menyatakan tidak loyal.

Hasil analisis statistik dengan uji chi square diperoleh $\mathrm{p}$ value $=0,079(p \geq 0,05)$ artinya tidak ada hubungan yang signifikan antara responsiveness dengan loyalitas pasien.

Parasuraman (1985) dalam Tjiptono (2002) responsiveness merupakan daya tanggap berkaitan dengan keinginan para staff untuk membantu para pelanggan dan memberikan pelayanan dengan tanggap.

Menurut asumsi peneliti berdasarkan data dilapangan responsiveness di Poli Obgyn sudah sangat baik, karena mulai dari pendaftaran hingga pelayanan tidak membuat pasien menunggu lama, sehingga pasien segera mendapat pelayanan yang dibutuhkan.

\section{d. Hubungan Assurance Dengan Loyalitas Pasien Rawat Jalan Poli Obgyn RSIA Eria Bunda Kota Pekanbaru Tahun 2016}

Berdasarkan hasil penelitian diketahui dari 97 bahwa 35 pasien yang menyatakan dengan assurance petugas yang tidak baik sebanyak 11 orang $(31,4 \%)$ pasien yang tidak loyal, sementara itu dari 97 bahwa 62 pasien yang menyatakan assurance petugas yang baik ada 15 orang $(24,2 \%)$ pasien yang menyatakan tidak loyal.

Hasil analisis statistik dengan uji chi square diperoleh $\mathrm{p}$ value $=0,593(p>0,05)$ artinya tidak ada hubungan yang signifikan antara assurance dengan loyalitas pasien.

Parasuraman (1985) dalam Tjiptono (2002)assurancemerupakan karyawan/staf memiliki kompetensi, kesopanan dan dapat dipercaya, bebas dari bahaya serta bebas dari resiko dan keragu-raguan. Dimensi-dimensi ini merefleksikan kompetensi perusahaan, keramahan (sopan, santun) kepada pelanggan, dan keamanan operasinya

Hasil penelitian yang dilakukan Agus Hufron (2008) dengan judul "Analisis Hubungan Persepsi Pasien Tentang Mutu Pelayanan Kesehatan Dengan Tingkat Kepuasan Pasien Di Puskesmas Penumping Kota Surakarta" membuktikan bahwa memang ada hubungan yang positif dan bermakna antara persepsi pasien tentang keyakinan dengan tingkat kepuasan pasien rawat jalan di Puskesmas Penumping.

Menurut asumsi peneliti pasien di poli obgyn RSIA Eria Bunda sudah merasakan assurance, karena para petugas pada saat memberikan pelayanan kepada pasien dapat memberikan rasa aman kepada pasien.

\section{e. Hubungan Empaty Dengan Loyalitas Pasien Rawat Jalan Poli Obgyn RSIA Eria Bunda Kota Pekanbaru Tahun 2016}

Berdasarkan hasil penelitian diketahui dari 97 bahwa 21 pasien yang menyatakan empaty petugas yang tidak baik sebanyak 10 orang $(47,6 \%)$ pasien yang tidak loyal, sementara itu dari 97 bahwa 76 paisen yang menyatakan empaty yang baik ada 16 orang $(21,1 \%)$ pasien yang menyatakan tidak loyal.

Hasil analisis statistik dengan uji chi square diperoleh $\mathrm{p}$ value $=0,031(p \leq 0,05)$ artinya ada hubungan yang signifikan antara empaty dengan loyalitas pasien. Analisis perbandingan hubungan kedua variabel diperoleh $\mathrm{POR}=3,4$.

Penelitian ini sejalan dengan penelitian Sulni, dkk (2013) mengenai hubungan mutu pelayanan kesehatan dengan loyalitas pasien di Puskesmas Baranti Kabupaten Sidrap Tahun 2013 dengan hasil penelitian menunjukkan bahwa ada hubungan yang bermakna antara empathy dengan loyalitas pasien p value $(0,001)$.

Empathy menunjukkan derajat perhatian yang diberikan kepada setiap pelanggan dan merefleksikan kemampuan kerja (karyawan) untuk menyelami perasaan pelanggan.

Menurut asumsi peneliti pasien di poli obgyn RSIA Eria Bunda Pekanbaru pasien kurang merasakan empati dari petugas, dan pasien 
merasa kurang mengerti dengan apa yang disampaikan oleh petugas. Para petugas hendaknya memberikan pelayanan terbaik kepada pasien agar pasien merasa nyaman dalam memeriksakan kesehatan, dan menggunakan bahasa yang mudah dimengerti oleh pasien.

\section{KESIMPULAN DAN SARAN Kesimpulan}

1. Adanya hubungan antara tangibles dengan loyalitas pasien. Hasil analisis statistic dengan uji chi square diperoleh $\mathrm{p}$ value $=0,046(p<0,05)$ dan nilai POR $=2,9$. Adanya responden yang menyatakan tangibles tidak baik disebabkan oleh ruang tunggu poli obgyn yang kurang bersih.

2. Ada nya hubungan antara reliability dengan loyalitas pasien. Hasil analisis statistic dengan uji chi square diperoleh $\mathrm{p}$ value $=0,007$, dan nilai $P O R=4$. Adanya pasien yang menjawab reliable yang tidak baik dilapangan disebabkan karena pasien merasa kurang puas dengan penjelasan yang diberikan oleh petugas kesehatan.

3. Tidak ada nya hubungan antara responsiveness dengan loyalitas pasien. Hasil analisis statistic dengan uji chi square diperoleh $\mathrm{p}$ value $=0,079$. Responsiveness di poli obgyn sudah sangat baik, karena mulai dari pendaftaran hingga pelayanan tidak membuat pasien menunggu lama, sehingga pasien segera mendapat pelayanan yang dibutuhkan.

4. Tidak adanya hubungan yang signifikan antara assurance dengan loyalitas pasien. Hasilan alisis statistic dengan uji chi square diperoleh $p$ value $=0,593$. Pasien di poli obgyn RSIA Eria Bunda sudah merasakan assurance, karena para petugas pada saat memberikan pelayanan kepada pasien dapat memeberikan rasa aman kepada pasien.

5. Adanya hubungan yang signifikan antara empathy dengan loyalita spasien. Hasil analisis statistic dengan uji chi square diperoleh $\mathrm{p}$ value $=0,031$, dan nilai POR $=3,4$

\section{SARAN}

Berdasarkan hasil penelitian dan pembahasan ada beberapa hal yang dapat di sarankan peneliti, kepada:

\section{RSIA Eria Bunda}

a. Meningkatkan kebersihan ruang tunggu poli obgyn RSIA Eria Bunda dengan cara meningkatkan peran pengawasan untuk memonitoring kerja petugas kebersihan di ruang tunggu poli obgyn RSIA Eria Bunda tersebut.

b. Sebaiknya RSIA Eria Bunda memberikan pelatihan atau penyuluhan kepada petugas mengenai cara berinteraksi dengan pasien sehingga pasien merasa puas dan loyal dengan pelayanan yang diberikan.

c. Para petugas hendaknya memberikan pelayanan terbaik kepada pasien agar merasa nyaman dalam memeriksakan kesehatan, dan menggunakan bahasa yang mudah dimengerti oleh pasien.

\section{Peneliti Selanjutnya}

Untuk peneliti selanjutnya sebaiknya dapat menyempurnakan penelitian ini dan lebih bisa meneliti dengan cakupan aspek variabel yang lebih luas.

\section{DAFTAR PUSTAKA}

Aditama, P.Y. (2010). Manajemen Administrasi Rumah Sakit. Gakanta: UI pres

Agus, G. (2008). Analisis Hubungan Persepsi Pasien Tentang Mutu Pelayanan Kesehatan Dengan Tingkat Kepuasan Pasien Di Puskesmas Penumping Kota Surakarta.

Ali Hasan., (2008), Marketing, Yogyakarta: Media Pressindo

Imasari, dkk. (2011). Pengaruh Relationship Management Terhadap Loyalitas Pelanggan Pada PT BCA Tbk. Jurnal Fokus Ekonomi Vol. 10, No. 3 ( http://www.unisbank.ac.id/ojs/index.php 
/fe2/article/viewFile/474/330 diakses pada tanggal 1 April 2016)

Kemenkes RI. (2009). Undang-undang RI No 44 Tahun 2009 Tentang Rumah Sakit. (binfar.kemkes.go.id/?wpdmact=process \&did=NTAuaG90bGluaw diakses pada tanggal 9 April 2016)

Kotler, P dan Keller, Kevin L. (2009). Manajemen Pemasaran. Jakarta: Erlangga.

Suhartanto. (2008). Pengaruh Kualitas Jasa Terhadap Loyalitas Pelanggan. (http://digilib.polban.ac.id/files/disk1/88 /jbptppolban-gdl-prilasaesa-4384-2bab2--0.pdf diakses pada tanggal 8 April 2016)

Sulni, Darmawansyah, indar. (2013). Hubungan Pelayanan Kesehatan Dengan Loyalitas Pasien di Puskesmas Baranti Kabupaten Sidrap Tahun 2013. (http://repository.unhas.ac.id/handle/12 $3456789 / 5416$ diakses pada tanggal 8 April 2016)

Tjiptono, F. (2002). Total Quality Management. Jakarta: Andi Offset. 